\title{
Regulation and Precariatisation of Working Life
}

\author{
Kurt Dauer Keller \\ Hanne Dauer Keller
}

Aalborg University

\begin{abstract}
The regulation of labour market attachment and working conditions now appears to be a thoroughly cultural and political issue, which is just as much a subjection to compulsory flexibility in association with the deregulation of collectively attained rights. Precarious working life is an age-old form of exploitation, expanding in our days to the academic fields of communication work and knowledge work. Sum and Jessop offer an approach to the theoretical understanding of this current epoch. However, their leaning on Foucault together with information science and systems science set a decisive limit to any phenomenological perspective of cultural and political experience - and thus hamper their project of outlining a cultural political economy. Still, Sum and Jessop's important contribution to the notion of a cultural political economy must be recognized, not least when it comes to grasping the precariatisation of academic knowledge work and communication work.
\end{abstract}

Keywords: Regulation, precariatisation, working life

\section{Introduction}

In the contemporary era of global capitalism, regulation of work takes place in diverse regimes with new modes and objects of governance. Political economy has developed into a phase of globally networked capital, while the power and sovereignty of nation states have turned into an unstable matter. Struggles over the role of digital capital versus labour power dominate expanding domains of communication and knowledge. And individualization has become a widespread condition of labour markets as well as of the organization and performance of work. Social scientist like Castells (2010) and Beck (Beck \& Beck-Gernsheim 2001) describe the new socioeconomic and sociocultural condition of global networks and exposed individual life. This new overall condition seems to constitute the framework for political and economic regulation as well as for social and cultural organization.

Social networks and individualities are, however, anthropological structures and entities that can't be entirely subsumed under regimes of capital accumulation. Sociality and individuality adhere to the sociocultural 'flesh' and labour power, which include capabilities like existential freedom, creativity and structuring of meaning (cf. Keller 2013). Thus, a most crucial matter of the regulation of work is about the ways in which these existential capabilities are organized (collectively and individually) in praxis and institutions that reflect, of course, the pertinent relations of political and economic power. Social life has been conceptualized along such lines by Foucault. But he does not directly explicate the realities or formalities of the regulation of work. For that purpose we may turn to Jessop and Sum's critique of the regulation approach and their suggestion of a cultural political economy. On that basis, it is possible to point out the importance of the corporeal experience of social meaning that Foucault has helped us to conceive. This is a framework for focusing on the regulation of important aspects of work, such as professionalism, knowledge, and existential freedom, in the perspective of labour power, civil society, and movements of resistance.

We appreciate the trans-disciplinary approach to cultural political economy that Sum and Jessop call for, and agree with them in insisting that the aspiration to transcend disciplinary boarders should be anchored in ethnographic details of realworld problems and occupied with logically coherent concepts, methods and reasoning that include ontological as well as epistemological and methodological topics. The scope and depth of their theoretical research are admirable, in particular as to the conceptualization of the cultural domain as a fundamental structuration within the political economy, whereby the very notion of regulation is also changed from conventional descriptions of five basic structural forms - the wage relation, the enterprise form and competition, money and credit, the state, and the international regimes, which reflect the institutional 
configuration of Fordism - to distinction of the inherent contradictions of a particular growth regime, so as to approach Weber in highlighting elements of political capitalism and in particular to follow Foucault's notion of discursive formation of domination and hegemony through social technologies that configure into what he called "dispositives" (Sum \& Jessop 2013: 208, 251). Taking on Foucault's micro-social perspective of social technology as the practice of power and knowledge that shapes objective rules and norms together with subjectivity and identity, the macro-social perspectives of Marx and Gramsci are preserved and reformed as unfolding and concretizing the 'why' matters of regulation and governance, while Foucault only answers the 'how' questions (pp. 205-214, 478). However, this brings us to the crucial problems concerning the conception of politics and culture in association with the socio-technical matters of regulation and governance. Sum and Jessop seem to neglect that questions of 'why' address either functionalist, teleological, or hermeneutic ontologies and epistemologies all of which they are (in line with Foucault) struggling to avoid. Foucault clarifyes how objective and subjective aspects of our social being are intertwined in the historical formation of meaningful structures of micro level practices and macro level institutions. But he is very foreign to the fundamental political and ethical concerns of freedom, lived experience and human life values, i.e. the entire phenomenological perspective that he knew well, partly incorporated as trivialities and partly refused strongly in his own thinking, and hopelessly attempted to reinvent in his last philosophical call for a new Socratic ethics. As it has been pointed out by Dreyfus \& Rabinow (1983) and also Han (2002), Foucault is occupied with structure to the extent of implying 'regularities' that regulate themselves. He takes our lived understanding of social practices and discourses for granted without explicating it.

Sum and Jessop apply information science and systems science concepts such as 'complexity' and 'selection' when it comes to basic notions of political and cultural ontology. This is quite unfortunate to their theoretical conception! They emphasize an existential or cultural 'necessity' of complexity reduction, which is what sense- and meaning-making (i.e. semiosis) is claimed to be about. The reduction of complexity is portrayed as fundamental to the lifeworld, lived experience, learning, and social imaginary that they take up as important aspects of the cultural being. Furthermore, the discursive and semiotic domain of meaning- and sense-making is discerned from the social reality, which is presented as a domain of material structuration. Thus, it is foundational to this cultural political economy that is places cultural semiosis on an equal ontological footing with the 'material' structuration of social relations and forms, as different but coupled forms of complexity reduction, whereby the evolution of new social order takes place through the three 'mechanisms' of variation, selection and retention. After all, human beings are construed as rational and computational actors who have to reduce complexity and make it calculable with certain codes and programmes that are associated with feeling, motives, etc. However, this is an altogether speculative ontology and anthropology! With that point of departure, there is hardly any political or cultural perspective with which to enhance Foucault's sociotechnical structuralism. Theoretical connection with people's actual experience of political and cultural matters is lacking.

Foucault has emphasized that power - the influence on the actions of others - is only really interesting in so far as these others maintain their freedom and take on the foreign influence through one's own willed actions. In particular, this is true of the issues of individualization that are pertinent to the late modernity. The technologies of the self that Foucault uncovered in the culture-historical genealogy of the modern project of self-realization are also formed through the needle eye of individual consciousness and will, whereby they are sedimented as instituted meaning and interpretation that binds the individual through its own experience. Nevertheless, the general notion of 'social technologies' in Foucault always leaves entirely open the decisive cultural and political question of subject-object status: how the subjected subjectivity relates to the lived subjectivity, how the regulated social identity of the individual relates to the individual's regulation of one's own social identity. Existential freedom follows from a certain awareness and reflection that is not pre-given with immediate forms of human perception, expression and emotion. We are, therefore, to a considerable extent de-centered in our own experience and behaviour, which has its pre-personal and anonymous levels and dimensions, where we are subject to political and cultural conditions and processes but not acting as considerate and responsible persons who take a stand in politics or ethics. Hence, the important distinction between 'the political' and 'politics' has been unfolded by Lefort, Nancy and others.

Sum and Jessop cogently analyze the notion of a knowledge-based economy and the quasi-commodification of knowledge and creativity as elements of the diffusion of neo-liberal policies. The knowledge-based economy is an imaginary regime of accumulation that has remained subordinate to the global rise of finance-dominated accumulation as well as its continuous crisis. Within the university sector in many European countries precarious employment relations and working conditions have become widespread through the latest decades, due to the neo-liberal policy of 'new public management' as well as the particularly feeble collective organization of university employed academics. In Denmark, for instance, a new 
university law in 2003 at a stroke substituted an ordinary enterprise organization for the academic and democratic forms of organization that has traditionally been characteristic to the universities. This situation illuminates an important aspects of the cultural political economy of knowledge work, namely how the ubiquitous capitalist problematic of individualization is in play as precariatisation of academic working life in the university sector.

\section{References}

[1] Beck, U. \& E. Beck-Gernsheim (2001). Individualization: Institutionalized Individualism and its Social and Political Consequences. Sage Publications.

[2] Castells, M. (2010). The Rise of the Network Society. 2nd Ed. Wiley-Blackwell

[3] Dreyfus, H. \& P. Rabinow (1983). Michel Foucault: Beyond Structuralism and Hermeneutics. University of Chicago Press.

[4] Han, B. (2002). Foucault's Critical Project. Stanford University Press.

[5] Keller, K.D (2013). 'Political Attitude in the Age of Globalization' in O.G. Augustin \& C. Ydesen (Eds.): PostCrisis Perspectives: The Common and its Powers. Peter Lang Edition.

[6] Sum, N.-L. \& B. Jessop (2013). Towards a Cultural Political Economy. Edward Elgar Publishing. 